\title{
Indicações sobre a descrição de cenários de produção jornalística
}

\section{Indications about the description of journalistic production scenario}

\author{
Marcelo Engel Bronosky \\ Professor doutor da Universidade Estadual de Ponta Grossa (UEPG) na graduação e Mestrado em Jornalismo, \\ coordena o Grupo de Pesquisa Lógicas de Produção e Consumo do jornalismo, vinculado à UEPG. \\ <mebrono@yahoo.com.br>
}

\section{Rafael Schoenherr}

Doutorando no Programa de Pós-Graduação em Gestão do Território na Universidade Estadual de Ponta Grossa (UEPG), professor colaborador no curso de jornalismo da UEPG.

$<$ rafaelschoenherr@gmail.com>

\section{RESUMO}

O artigo pretende apresentar mapa dos esforços descritivos dos processos sócio-interacionais em ambientes de produção jornalística. Procura-se, desta forma, estabelecer aproximação em relação a um quadro teórico-metodológico de investigação da esfera jornalística calcado na observação e descrição sistemática de cenários onde se processam regras, estratégias, táticas e tensões do campo jornalístico. $\mathrm{O}$ texto pretende assinalar a presença de um aporte ou conjunto de referências teóricas e discussões sobre a prática jornalística que orienta a compreensão da notícia pela observação e análise da ordem da interação entre os atores. Tal esforço tem por objetivo oferecer igualmente apontamentos no sentido de orientar investigações em torno de estratégicas metodológicas de vertente etnográfica, limitada no campo de estudos do jornalismo atualmente

Palavras-chave: Cultura jornalística. Sócio-interação. Etnografia.

\begin{abstract}
This article aims to present descriptive map of the efforts of social-interaction processes in journalism production environments. It's wanted, thus to establish approach in relation to a theoretical and methodological framework for research of journalistic sphere trampled on observation and systematic description of scenarios where the processing rules, strategies, tactics and tensions of the journalistic field. The text intends to signal the presence of a supply or set of theoretical references and discussions of journalistic practice that guides the understanding of news by observing and analyzing the order of interaction between actors. This effort aims to also offer notes in guiding investigations into methodological strategic ethnographic aspect, delimited in the study of journalism field today.
\end{abstract}

Keywords: Journalistic culture. Social-interaction. Ethnography.

\section{Introdução}

"Para Malinowski, o comportamento concreto de seres humanos reais é o ponto de partida necessário, a referência constante e a verificação última de toda pesquisa" (Durham, 1986, p. 13) 
Este texto tem por objetivo apresentar apontamentos sobre os usos da etnografia para os estudos do jornalismo. Pretende-se recorrer a marcações gerais da etnografia nos estudos sociais e da cultura com o objetivo indireto, para além deste artigo, de embasar uma abordagem teórico-metodológica dos fenômenos, padrões e das regras de interação na produção e no consumo em jornalismo. De modo mais direto, trata-se de uma proposta de aproximação com vistas à descrição de cenários jornalísticos (em sua complexidade) e de sinalização das possíveis implicações desse tipo de "entrada" no estudo do jornalismo.

De uns anos para cá, a etnografia passou a ser utilizada com mais intensidade em reflexões que envolvem o jornalismo, não que ela já não aparecesse de forma indireta nas pesquisas do campo. Alguns sinais já poderiam ser vistos nas décadas iniciais do século XX, a partir das reflexões de Robert Park (2008) e o jornalismo como conhecimento. Entretanto, este, assim como outros esforços, estava preocupado em estudar, entre outras coisas, a formação da cultura jornalística e suas implicações na definição da notícia. Ora, os estudos culturais, entendidos aqui não como ramo do conhecimento, mas também por isso mesmo, mantêm fortes aproximações com este modo de investigação, na medida em que está preocupado com as manifestações sociais e humanas, coletivas e individuais, para, a partir dela, reconhecer a complexidade que forma a própria cultura. Este avanço propiciou também um interesse maior por investigações que tivessem como centro as múltiplas relações que se estabelecem entre os sujeitos e entre os sujeitos e os objetos.

Antes, porém, cabe fazer uma retomada da presença da etnografia nos estudos sociais a fim de demarcar certo percurso teórico-metodológico até se encontrar com o jornalismo. Trata-se de um ramo ou técnica de vertente antropológica com origem no início do século XX, que tem em Bronislow Malinowski seu principal expoente. Ela se estrutura na observação sistemática e detalhada de situações e fenômenos presentes. Como relata Eunice Durham (1986), na coletânea sobre o autor, Malinowski desenvolveu seus estudos em comunidade tribais, caracterizadas por terem pouco ou quase nenhum contato com outras civilizações. "A vivência da situação de campo e as características da sociedade trobriandesa (Austrália) forneceram os materiais com os quais desenvolveu sua visão particular do objeto e do método da antropologia" (Durhan, 1986. p. 9).

Registra-se aí uma novidade nos encaminhamentos da pesquisa de campo, pois o pesquisador precisa dirigir-se à tribo ou à coletividade em questão e ter um contato estendido no tempo para apreensão do comportamento alheio/ 
distante. Isso marca uma ruptura em relação à etnografia de fins do século XIX, marcada pela pesquisa de gabinete ou a delegação do trabalho de campo a missionários e viajantes. No entender de Winkin (1998), configura-se aí, nas duas décadas iniciais do século XX, a primeira revolução etnográfica.

É uma primeira revolução, pois, de um lado, o antropólogo é e permanece durante muito tempo no campo mesmo, e, por outro lado, não encara mais aquele que observa como graciosos animais exóticos, mas, sim, como pessoas dignas de respeito, cuja vida social se deve tentar reconstituir por observação às vezes participante (Winkin, 1998, p. 130).

A partir de descrição de tais sociedades, os antropólogos ofereceram um rico material de análise, na busca de identificar rituais de iniciação, elementos que identificassem as relações de honra, hierárquicas entre outros fatores que constituíram a identidade e a formação ou não dos grupos. Tais experimentações foram aplicadas para compreender as sociedades/identidades tidas como ordinárias. Com o passar dos anos, tal técnica passou a ser utilizada igualmente para estudos de comunidades urbanas, onde os níveis de relacionamento são mais fluídos, exigindo olhares mais apurados e técnicas mais eficientes. Nesse sentido, a pesquisa passou a ser empregada em estudos culturais, multiculturais e interacionistas simbólicos. A transformação metodológica está em se orientar não mais somente pelo distante geográfica e culturalmente, mas por campos de trabalho e análise na própria sociedade (ou de microssociedades) - com implicações e desafios particulares.

Uma tática de pesquisa pertinente ou princípio que se desenvolve nessa linha é de realmente circular pela cidade para se fazer ciência social, ou entender o ambiente urbano como "laboratório natural" (Winkin, 1998, p. 131), como pontuou a Escola de Chicago. Fica sugerida nessa "manobra" da sociologia a ideia ainda válida de que há uma relação entre esse novo contexto (o crescimento das cidades e do espaço urbano propriamente dito) e as formas comunicacionais ou interações simbólicas'.

A etnografia agrega, assim, a riqueza e também o complicador se sair de um ponto de vista eminentemente externo sobre a cultura (alheia, distante, isolada e até exótica) e voltar-se ao estudo da cultura próxima ou a que se pertence no contexto das cidades (e não mais apenas da floresta). Marca dessa

1 O jornalista Joseph Roth, no livro-reportagem Berlim, faz observação de relevante analogia, nesse sentido, ao comparar os acontecimentos em manchetes garrafais na primeira página dos jornais ao menino que grita os títulos nas esquinas de Berlim e tenta assim chamar a atenção de quem passa. $O$ contexto urbano condiciona uma fala midiática específica e é condicionado por esta última. Relação que voltaremos a comentar ao fim deste artigo. 
transição é o fato de que, inicialmente, certos lugares e grupos são preferidos no ambiente urbano - em geral, marginalizados e estigmatizados. Algo como uma tendência a manter o ponto de vista externo sobre nós mesmos na condição de exóticos².

Pode-se ler na trajetória da etnografia (e talvez seja essa a tentativa do presente artigo) reorientações de requintes metodológicos em termos de estratégias (não excludentes) de ida a campo, registro e exposição dos resultados com vistas à análise da cultura. Se não interessa mais apenas o exótico e o distante e sim a própria cultura, passam a ser pertinentes modos de ver ou técnicas que deem conta de perceber variações dentro dessa cultura própria ou próxima. Torna-se ímpar contemplar variações e exigências do "procedimento etnográfico dentro de nossa própria sociedade" (Winkin, 1998, p. 132).

Entretanto, a vida cotidiana se faz predominantemente em lugares outros que não áreas de vulnerabilidade, de cerceamento, conflito evidente, marginalidade em relação a normas ou ambiente estigmatizados do espaço urbano. Nessa lógica, tão importante quanto à formação de grupos de fronteiras nítidas e institucionalizadas são também os "ajuntamentos" (Goffman, 2010) que coordenam suas/nossas condutas no espaço público em função de outros desconhecidos que pertencem ao mesmo tráfego ou espaço de circulação. Parece-nos relevante o fato de se ter que lidar com situações em que se perdem as fronteiras nítidas do campo de estudo também para o estudo do jornalismo.

No momento, ressalta-se que os campos de trabalho da etnografia abandonam gradativamente as "ilhas" e passam a ser configurados também por "múltiplas microssociedades formais e informais" (Winkin, 1998, p. 131) que ajudamos a compor cotidianamente. $O$ interesse por esses outros objetos leva, segundo o autor, a uma terceira revolução etnográfica - uma tentativa de apreender e analisar o que se mobiliza para "fazer parte" de um grupo ou de uma situação. Seja ela, poderíamos pensar o bar da esquina, a sala de aula, a família, o trabalho, a praça pública, a banca de revistas ou, por extensão, a redação de um jornal.

2 Valeria aqui pensar se não reproduzimos essa tendência nos estudos do jornalismo quando escolheremos arbitrariamente grandes redações ou as maiores empresas jornalísticas para nossas pesquisas de campo, ao passo que a maior parte do jornalismo não é feita aí e as redações em cidades médias e pequenas não necessariamente funcionam nos mesmos termos. Trata-se de cotejar, minimamente, as condições históricas, mercadológicas e industriais em que se forjou a própria noção de notícia, entre outros valores elementares da atividade profissional jornalística. 
As pesquisas de campo, de forma geral, objetivam identificar, a partir de caracterização e determinação de cenários, situações e/ou marcas, que se desenvolvem na "ordem da interação". A considerar, na perspectiva de Goffman (1999), que o mundo social também se faz e se reinventa na ordem da interação - tão relevante ao analista quanto as ordens econômica, política e jurídica -, pode-se tensionar os estudos do jornalismo no sentido de que as lógicas de produção e consumo em jornalismo também podem ser apreendidas na ordem da interação. Nessa linha, "toda infração da ordem de interação, toda ruptura das regras que regem a interação são igualmente rupturas da ordem social" (Winkin, 1998, p. 137). Aqui talvez seja possível se pensar uma chave para o estudo dos pontos de tensão que cercam e perfazem as circunstâncias de produção e consumo em jornalismo desde o âmbito interacional.

Um esforço descritivo de consulta obrigatória para fins de trabalho nesse sentido é o clássico ensaio do historiador Robert Darnton (1990): "Toda notícia que couber a gente publica". Neste documento, ele relata suas experiências quando repórter do New York Times, nos anos de 1980, revelando forte aproximação com técnicas já consagradas no campo da etnografia. Entre elas, as pesquisas de campo.

Em primeiro lugar, o então repórter toma a sala de redação do jornal como campo de presença e observação (no caso, participante). É onde se conformam as condutas e as regras que vão decidir o que "cabe" como notícia no dia seguinte. O segundo ponto é a tentativa de descrever a sala no espaço, ou como as divisões de poder nas relações de trabalho acompanham a estruturação de setores ou regiões na redação. Pratica-se uma espécie de topografia do ambiente de produção jornalística que rompe com a presunção talvez sugerida por muita leitura da sociologia do trabalho do ambiente produtivo como bloco monolítico ou homogêneo - aqui podemos visualizar distinções na simples ocupação do espaço e suas repercussões nas relações e decisões produtivas.

Simultaneamente, busca-se compreender a formação de grupos e a relação entre grupos - tem a ver com identificar como a "tribo jornalística" passa a partilhar valores, mas também a como a circunstância interacional mais próxima (face a face), o grupo de referência, decide o que é e como é a notícia mais importante do dia seguinte. Não à toa, um dos grupos de referência na conformação do que será produzido é composto pelas fontes de informação e outro pelos pares, como os demais repórteres em comentários informais ou a expectativa da leitura a ser feita pelo revisor/editor. Interessa notar que atenção do observador se volta tanto às relações entre grupos internos à redação quanto à relação entre elementos de um mesmo grupo, de grupos diferenciados 
e entre grupo interno e externo ao jornal, para se ter uma ideia sugestiva da complexidade metodológica possível no âmbito interacional. A coleta de dados em presença dos informantes, o registro de conversas informais, de "lemas" entre repórteres, a procura por distinções entre grupos e subgrupos e mesmo o breve mapa espacial remetem a estratégias descritivas muito próximas da etnografia (ou uma possível etnografia das redações). Por fim, busca-se não anular um dos elementos ao estudar ou contemplar o outro, mas insinua-se aí a composição de um cenário de expressão da cultura jornalística.

Nesse esforço etnográfico, torna-se fundamental constituir elementos que, conforme enquadramentos definidos, busque compreender a circulação dos sujeitos nestes espaços, bem como a ocupação dos objetos nestes lugares e suas ligações ou não com os sujeitos. O conjunto de elementos deve ser compreendido nas suas múltiplas relações, sem as quais, perderíamos a compreensão do todo.

A etnografia exige dos pesquisadores a capacidade de criar uma"imagem" dos fenômenos e situações nas quais os sujeitos estejam envolvidos. Era isto que se dizia de Malinowski: "[Ele tinha] habilidade de criar, para o leitor, a imagem viva e humana de um povo completamente diferente de nós" (Durham, 1986, p. 9). Essa característica de entender a cultura como quem tenta ler (ou construir uma leitura de) um manuscrito estranho leva Geertz (1989, p. 7) a conceituar a etnografia como "o esforço intelectual por uma descrição densa da cultura". O desafio seria apreender e apresentar uma multiplicidade de estruturas conceituais complexas.

Longe de equivaler e mesmo polemizar o trabalho de ambos os antropólogos, interessa ressaltar uma referência aí partilhada de que essa imagem da diferença ou o estranhamento de quem lê um relato etnográfico e pensa "não me situo entre eles, não pertenço a isso" resulta tanto do trabalho de campo quanto da escrita e do contraste com a teoria. Isto é, para nossos fins mais modestos poderíamos pensar que: aproximar-se das especificidades de certa cultura envolve esforços teórico-metodológicos que compreendem (a) acesso ao campo e observação sistemática/controlada; (b) técnicas de registro e releitura dos diários de campo; e (c) apresentação fundamentada das interpretações. A etnografia pode ser entendida então como arte e disciplina científica que convoca três competências: saber ver, saber estar com e saber escrever - a um terceiro (Winkin, 1998).

Esta capacidade de registro/exposição da diferença, que em outros métodos de pesquisa está baseado no simples ordenamento dos fatos, cobra - nesse caso - um esforço de elaboração minuciosa das situações nas quais os 
fenômenos e os sujeitos estejam envolvidos, para que - de posse deste conteúdo -, encontrar correlações, contiguidades, tensões e rotinas, materializados entre os povos e seus investigadores, entre os sujeitos e os objetos de investigação.

A lógica neste esforço de pesquisa diz respeito, entre outros fatores, a reconhecer as discrepâncias, os desregramentos, as descontinuidades, as rupturas, tudo aquilo que se refere ao diferente, ao inusitado, como objeto de análise e interpretação. Só a partir disto, torna-se possível estabelecer sentido e compreender aquilo que chamamos de "normal", de "coerente", de "natural", de "rotina". Goffman (2010) faz menção semelhante ao ressaltar a contribuição ambígua de psiquiatras ao notarem comportamentos de pacientes não apropriados para a situação. "De modo geral, o estudo psiquiátrico de impropriedade situacionais levou à observação do infrator ao invés das regras e círculos sociais que são ofendidos" (Goffman, 2010, p. 13). O apontamento certamente merece correlações na descrição de cenários de produção jornalística.

Quando se traz para o estudo de situações urbanas, ou seja, para o espaço das manifestações jornalísticas, o esforço se complexifica ainda mais, pois os agentes passam a assumir posição mais fluída frente as situações do cotidiano. A literatura na área está repleta de exemplos da multiplicidade de identidades adotadas pelos sujeitos na contemporaneidade. Uma mulher de meia idade pode, por exemplo, nas primeiras horas do dia, assumir sua posição de mãe e dona de casa, para logo em seguida torna-se líder empresarial; na sequência assumiria sua função de cozinheira ou atleta numa praça qualquer de uma cidade qualquer. Esta multiplicidade de posições assumidas diariamente contribuiu para dificultar as análises, como mostra Kellner (2001) ao identificar as posições de sujeitos manifestadas pelos personagens do seriado Miami Vice. É justamente nestes espaços que os etnógrafos estabelecem suas bases, num esforço de identificar os "palcos" onde representam os vários "atores" sociais e suas várias "encenações".

Essa marca de fluidez de papéis e posições em microssociedades que se montam e desmontam ao longo do dia também se expressa nos contextos de produção e consumo do jornalismo. Logo, representa entraves metodológicos de percepção, descrição e análise. As fronteiras do ambiente de trabalho jornalístico não são exatamente nítidas, assim como não há um leitor profissional de jornal, mas um trabalhador ou estudante que em certa circunstância se configura leitor. A sala de redação é um espaço privilegiado de observação das interações produtivas, o que não elimina a presença de outros laços de filiação, círculos de relação, empatia e tensões relevantes para além da 
ocupação trabalhista e mesmo para além da redação. Daí a restrição da teoria organizacional do jornalismo destacada por Traquina (2005) também de outras clivagens de cunho empresarial-trabalhista desse tipo singular de produção simbólica que implica um modo específico de ser/estar, ver, agir e narrar o mundo (Traquina, 2005).

Contudo, o problema de investigar neste cenário não para por aí. Metodologicamente, a etnografia é criticada por ser essencialmente interpretativa, carecendo de rigor científico, e que por isso, os pesquisadores não fariam ciência, mas sim literatura. A segunda crítica diz respeito à presença do investigador em contato com os sujeitos investigados "contaminando" as informações coletadas.

Sobre a primeira, podemos afirmar que, assim como outros recursos metodológicos de matriz científicas baseados nas áreas humanas e sociais aplicadas, esta também assume relativa carga interpretativa quando destinada a analisar dados. Ou seja, se o problema é "o nível de" interpretação em jogo o que, portanto, decidirá se um esforço é ou não científico? Pensamos que, diante do nível de fluidez dos estudos etnográficos, a questão diz respeito ao fato de que a etnografia é uma técnica de captação e análise de dados, e não um método científico propriamente dito, assim como análise de conteúdo, por exemplo. Conquanto, podemos reconhecer que estamos falando de estratégias metodológicas e não de suportes metodológicos.

Ainda sobre esta crítica, podemos identificar que estudos desta ordem procuram focalizar aspectos específicos diante do conjunto mais amplo e que por ser específico, não poderia ser generalizável. Pensamos que esta crítica tem a ver com a tradição cartesiana das ciências físicas, que durante séculos, tem tensionado a trajetória metodológica das ciências sociais e humanas. Tal tradição cobrava a validação como essencial para dizer se algo é científico: todo estudo para ser considerado científico deverá, em se aplicando os mesmos métodos aos mesmos objetos, obter os mesmos resultados. Naturalmente, a complexidade social tem exigido outras abordagens, afinal a própria física já reconhece a insuficiência metodológica na identificação de fenômenos físicos, produzindo teorias como a dos Fractais, do Caos, por exemplo. Não obstante a esta realidade, a ciência produzida a partir de recursos etnográficos exige mais que um arrazoado de conteúdos, mas principalmente que deles emerjam dados que, articuladamente, produzam conclusões possíveis e sustentáveis. Conclusões estas reconhecidas nas suas limitações metodológicas, obviamente.

Quanto ao segundo aspecto, o debate é mais vigoroso, pois remete às questões envolvendo subjetividade $\mathrm{X}$ objetividade. Neste caso, duas 
"saídas" se apresentam de forma mais pragmática para o pesquisador: a primeira é reconhecer sua presença como exógena, e que está diferença só será superada, em partes, com o tempo - que é variável, de acordo com cada cenário, comunidade etc. Outro fator diz respeito, a saber, que, por mais que você interaja com o grupo de investigados, a distância garante liberdade de análise. Este paradoxo se aproximar para romper a indiferença tem o limite do comprometimento das análises. Para tanto, se faz necessário, como pressuposto, descrever detalhadamente sua posição em relação aos seus observáveis e como eles reagem a sua presença nos vários momentos da pesquisa. Desta forma, podemos nos aproximar da precisão dos dados, oferecendo aos nossos intelectuais possibilidades de compreender as múltiplas e variáveis (inter) relações que se constituem no ambiente pesquisado.

Por fim, pretende-se agora, tendo em vista o percurso desenvolvido de apontamentos sobre contribuições etnográficas, alinhavar indicações, em tópicos, sobre a descrição de cenários de produção jornalística a fim de proporcionar um quadro amplificado de movimentos possíveis da pesquisa etnográfica aplicada a objetos jornalísticos.

\section{Parâmetros gerais para descrição de cenários de produção jornalística}

A relação de parâmetros que segue busca agregar possíveis técnicas, estratégias, limites e desafios do uso etnográfico no estudo da produção jornalística via descrição de cenários. São indicações com vistas ao debate para criação de procedimentos e orientações teórico-metodológicas e não funcionam certamente como protocolo pronto de análise ou como dispositivo aplicável de imediato às realidades sob investigação - o que seria, de antemão, desconsiderar justamente a especificidade da cultura jornalística e dos quadros interacionais em questão.

A modificação da etnografia acompanhou a própria redefinição do conceito de cultura - a redução do conceito de cultura a uma dimensão justa, como quer Geertz (1989, p. 3), afastando-se da ideia demasiado ampla de um todo mais complexo. Em termos conceituais, uma definição "justa" de cultura jornalística, que não seja larga a ponto de não se tornar operacional e para nada servir, efetivamente, atua nos limites do trabalho de campo de observação da composição de cenários. Duas referências podem aqui ser úteis: a cultura dos jornalistas como um modo específico de ver, narrar e proceder (Traquina, 2005) - calcada em valores como o imediato, o realismo e a atualidade - e a cultura (em Malinowski) como unidade/síntese envolvendo materialidades, relações 
sociais e representações simbólicas (Durhan, 1986, p. 11). Uma terceira noção articuladora das duas anteriores e que converge à ideia de tribo é de que cultura é o que é "tudo o que é preciso saber para ser membro" (Winkin, 1998, p. 131);

Cenários não são constituídos apenas por objetos fixos ou relações estáveis (como pano de fundo), mas também variações, processos, ações e desenhos cambiantes. Os estudos etnográficos oferecem condições de qualificar a identificação de cenários complexos e móveis, comportamento dos sujeitos e as relações dos sujeitos com os objetos; através de estratégias observacionais, oferecem condições para articular múltiplos enquadramentos;

O cenário de produção jornalística, por sua natureza e a princípio, possui marcações objetivas que podem prevenir, ou melhor, informar (via literatura habitual da área) estratégias de pesquisa de campo, tais como: finalidade produtiva; ambiente de trabalho; regramentos no tempo e no espaço conhecidos como rotinas e etapas produtivas; hierarquia funcional; ritmo; acesso regular a outros contextos e a outras "tribos"; combinação particular do individual e do coletivo na produção (a questão autoral e o desempenho individual são valorizados na cultura jornalística);

A característica privada, ou no máximo semipública, da sala de redação acrescenta um complicador às investidas de campo, principalmente no que tange às três exigências da etnografia (Winkin, 1998, p. 133-134) - lugar acessível, observação sistematizável e idas e vidas entre observações de campo e teoria. Os condicionantes do ambiente não devem impedir o pesquisador de realizar mapas espaço-temporais, fluxos, ritmos, ciclos, bem como identificar limites ou fronteiras do campo de pesquisa;

Podem ser considerados múltiplos "lugares" de interação: entre jornalistas na redação; o repórter com o ambiente "rua"; entre repórteres em eventos/ coberturas afins; em espaços de convivência extraprodução, espaços culturais e em redes de sociabilidade; entre jornalista e fonte; redação/leitor. $O$ ajustamento ou encaixe entre os atores revela a ordem da interação prezada pelas instâncias de produção jornalística. Novamente, tensões/rupturas da ordem da interação, ou desregramentos, podem ser úteis no reconhecimento daquilo que foi violado;

Ainda não compartilhamos técnicas de registro ou de construção de cadernos de anotação de campo tanto quanto a antropologia. Mas certamente especificidades de nosso campo de investigação devem gerar táticas mais adequadas ou particulares aos estudos do jornalismo e da tribo jornalística. Mas as recomendações etnográficas de anotação e releitura do diário de campo para identificação, processual, de "regularidades" ou patterns continua valendo. O procedimento é vital na combinação de distanciamento (na medida em que 
se observa outra cultura) e inteligibilidade (na medida em que se apresenta essa cultura a um terceiro). A qualidade da coleta está diretamente associada ao reconhecimento da especificidade de uma cultura (e dos traços de continuidade entre culturas).

A comunidade interpretativa dos jornalistas caracteriza-se por sustentar uma interpretação compartilhada do mundo (Zelizer, 2000). A autora parece levar em conta a informalidade, a circunstância, interações face a face e também as mediadas, bem como os regramentos institucionalizados. Pode-se entender o jornalismo com base em grupos de pertencimento e de filiação (dos seus produtores). Os estudos de socialização entre os pares em redação oferecem sugestões de abordagem e poderiam ser recuperados.

Como técnicas ligadas aos estudos etnográficos, tem-se, entre outras:

Observação: voltada a identificação, a partir do preenchimento detalhado e minucioso de diários de campo, contendo cenários e a posição dos sujeitos nestes cenários.

Pesquisa participante/pesquisação: (esforço metodológico que visa reconhecer características a partir do contato direto com os sujeitos e objetos da pesquisa contemporâneos, com ou sem contato direto entre investigador e investigado;

História Oral: esforço de identificar/construir a partir da manifestação se sujeito(s) momentos passados de determinado fenômeno, época, momentos ou mesmo outros sujeitos e objetos;

Focus Grup e suas variações: análise a partir de grupos de controle. Muito utilizada em pesquisa de mercado, na qual os informantes, a partir de estímulos determinados, reagem, indicando dados. Criticado por não oferecer as condições ideais de consumo existentes na realidade. Valeria acatar sugestão sobre pesquisa de campo de Winkin (1998, p. 144) de entender os lugares ou contextos como "reservatórios de comportamento", no sentido inicialmente discutido de que, em hipótese, agimos comunicacionalmente em resposta a contextos determinados. O que seria dizer que certos comportamentos só ocorrem em certos lugares ou de que, no mínimo, existe aí um ajuste entre forma comunicacional e ambiente de interação. Esta última colocação levaria a investigar de que modo à forma (comunicacional) notícia existe e se aplica aos lugares/contextos e, ao mesmo tempo, ela é uma reação manifestação desses lugares/contextos determinados. 


\section{REFERÊNCIAS}

DARNTON, Robert. Jornalismo: toda notícia que couber a gente publica. In: $\mathbf{O}$ beijo de Lamourette: Mídia, cultura e revolução. São Paulo: Companhia das Letras, 1990, p. 76-109.

DURHAM, Eunice Ribeiro (org.). Malinowski. São Paulo: Ática, 1986.

GEERTZ, Clifford. A interpretação das culturas. Rio de Janeiro: LTC, 1989.

GOFFMAN, Erving. Comportamento em lugares públicos. Petrópolis: Vozes, 2010.

. Os momentos e os seus homens. Lisboa: Relógio D'Água, 1999.

A representação do eu na vida cotidiana. Petrópolis: Vozes, 1999.

KELLNER, Douglas. A Cultura da Mídia: estudos culturais entre o moderno e o pósmoderno. Bauru: Edusc, 2001.

PARK, Robert. A notícia como forma de conhecimento. In: BERGER, Christa; MAROCCO, Beatriz (Org.). A Era glacial do jornalismo: teorias sociais da imprensa. Porto Alegre: Sulina, 2008.

ROTH, Joseph. Berlim. São Paulo: Companhia das Letras, 2006.

TRAQUINA, Nelson. Teorias do Jornalismo: a tribo jornalística - uma comunidade interpretativa transnacional. Florianópolis: Insular, 2005.

. Jornalismo 2000. Revista de Comunicação e Linguagens. Lisboa: Relógio D'água Editorial, 2000.

WINKIN, Yves. A Nova Comunicação: da teoria ao trabalho de campo. Campinas: Papirus, 1998.

ZELIZER, Barbie. Os jornalistas enquanto comunidade interpretativa. In: Revista de Comunicação \& Linguagens, n. 27, p. 33-61, 2000.

Recebido em: 10/12/2015

Aceito em: 28/12/2015

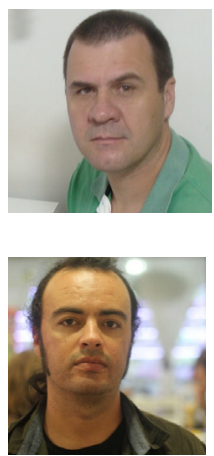

Endereço dos autores:

Marcelo Engel Bronosky <mebrono@yahoo.com.br>

http://lattes.cnpq.br/0515651302685104

Universidade Estadual de Ponta Grossa (UEPG)

Av. General Carlos Cavalcanti, 4748 - Campus de Uvaranas

84030-900 - Ponta Grossa - Paraná - Brasil

Rafael Schoenherr < rafaelschoenherr@gmail.com>

http://lattes.cnpq.br/4452688347961719

Universidade Estadual de Ponta Grossa (UEPG)

Av. General Carlos Cavalcanti, 4748 - Campus de Uvaranas

84030-900 - Ponta Grossa - Paraná - Brasil 